\title{
Associated Factors of maternal satisfaction towards delivery service among mothers who gave birth at Jimma Medical Center, Jimma Town, Southwest Ethiopia
}

\author{
Lalisa Ayele Woldasemayat ( $\sim$ lalisaayele@yahoo.com ) \\ Jimma University https://orcid.org/0000-0002-4368-0283 \\ Gadisa Bekele Badada \\ Jimma University \\ Melkamu Gelan Negasa \\ Jimma University
}

\section{Research}

Keywords: Satisfaction, delivery service, Jimma Medical Center, Ethiopia

Posted Date: December 4th, 2020

DOI: https://doi.org/10.21203/rs.3.rs-119068/v1

License: (c) (i) This work is licensed under a Creative Commons Attribution 4.0 International License.

Read Full License 


\section{Abstract}

Background and aim: Assurance of health care for all segments of the population with special attention given to women and children was one of the top priorities in Ethiopian health policy. Maternal and newborn deaths are heavily concentrated at the period of delivery and early postpartum. Thus, this study aimed to assess Associated Factors with maternal satisfaction towards delivery service among mothers who gave birth at Jimma Medical Center, Jimma Town, Southwest Ethiopia.

Methods: Institutional based cross-sectional study using face to face interview was conducted in Jimma Medical Center from April 01 to May 30, 2019. A systematic sampling technique was used to select 217 study participants using a semi-structured administered questionnaire.

Results: The maternal satisfaction level with the delivery services rendered at the hospital was $66.8 \%$. Delivering mothers satisfaction was found to be associated with educational status $\left(X^{2}=85.4, p<0.001\right)$, parity $\left(X^{2}=19.2, p<0.001\right)$, distance from health facility $\left(X^{2}=13.5, p<0.001\right)$, Monthly income $\left(X^{2}=13.8\right.$, $p<0.001)$, waiting time $\left(X^{2}=5.7, p<0.05\right)$, Cleanness of delivery area $\left(X^{2}=9.3, p<0.001\right)$.

Conclusion: The magnitude of mothers satisfied with the delivery service was low compared to studies conducted in Ethiopia so far. Maternal educational status, parity, distance from the health facility, waiting time, and monthly income were associated with mothers' satisfaction with delivery service. Therefore, awareness creation should be given for the community for improving the quality of delivery service and further study should be done on the knowledge and skill of health care providers on delivery service.

\section{Introduction}

Maternal satisfaction with delivery service is used to measure the ability of services provided to meet consumers' expectations. Satisfying women with the care given during labor and delivery helps to develop a positive childbirth experience and a favorable attitude towards motherhood. Also, satisfied clients have a higher chance to return to the facility in the future and recommend the institution to their neighbors and relatives (1).

Maternal, newborn, and child health is of paramount importance in the strategy to attain a healthy and productive population. Each year in Africa, 30 million women become pregnant, and 18 million give birth at home without skilled care and 700 women die of pregnancy-related causes, 3,100 newborns die, and another 2,400 are stillborn and 9,600 children die after their first month of life and before their fifth birthday for Each day in Africa. (2).

Childbirth conditions and its process are some of the significant life events to a woman. The time of childbirth as well as shortly thereafter is the most dangerous period in a child and mother's life.

Maternal and newborn deaths are heavily concentrated at the period of delivery and one week following the delivery, as evident in 50\% of all maternal and newborn deaths occur in the first 24 hours of birth (3). 
The proportion of mothers who were satisfied with delivery care in this study was $61.9 \%$. Women's satisfaction with delivery care was associated with the wanted status of the pregnancy, immediate maternal condition after delivery, waiting time to see the health worker, availability of waiting area, care providers' measure taken to assure privacy during examinations, and amount of cost paid for service. (4).

Satisfaction is a statement reporting quality of service and relationship between caregiver and patient measured by comparing quality services and patient's expectations. Although there has been a substantial decline in the annual number of maternal deaths, an estimated 273,500 women die each year as a result of maternal causes where sub-Saharan Africa and southern Asia account for $85 \%$ of the global burden (5).

The proportion of pregnant women who had given birth at health institution were $31.4 \%$ who had followed ANC for recent pregnancy, only $22.9 \%$ gave birth at the health institution. Factors associated with health institution delivery were the number of pregnancies (three and above) and difficult labor. However, difficulty labor/prolonged has remained a significant predictor of institutional delivery (6).

Unfortunately, in Ethiopia ANC coverage at least one visit and four visits are $42.5 \%$ and $19.1 \%$ respectively. Birth attended by a skilled provider is about $10 \%$ and $9.9 \%$ were in a health facility. The EDHS 2016 reveals that only $18.8 \%$ of births were delivered in a health facility in the Oromia region. In Ethiopia according to the latest estimation, the maternal mortality rate has declined from 676/100,000 live births in 2011 to 412/100,000 live births in 2016 EDHS 2016 (7).

The maternal mortality ratio in developing countries in 2013 is 230/100,000 live births. The major complication that accounts for nearly $75 \%$ of all maternal deaths are bleeding, especially following childbirth, sepsis, and prolonged or obstructed labor (8).

This study was intended to assess the level of maternal satisfaction on delivery services, identify the factors affecting maternal satisfaction, provide a recommendation to improve the quality of delivery service, would be helpful to fill research knowledge gaps and to improve the level of maternal satisfaction in Jimma Medical Center.

\section{Methods And Materials}

The institutional-based cross-sectional study design was conducted in Jimma Medical Center (JMC)which is the only teaching and referral hospital in the southwestern part of the country and giving service for about 15-20 million population from different parts of Southwest Ethiopia. Jimma Medical Center is found on $346 \mathrm{~km}$ far from Addis Ababa, the Capital city of Ethiopia. The study was conducted from April 01/2019 to May 30/2019. Study participants were selected from mothers who gave birth at JMC during the data collection period. All mothers who attend delivery services in the study Hospital were included in the study and those critically/mentally ill clients or unable to communicate appropriately were excluded from the study. The sample size was determined as single population proportion formula ( $n=$ $(Z a) / 2) 2 \mathrm{P}(1 \square \mathrm{P}) / d^{2}$ ) by considering taking the prevalence of mothers satisfied with delivery service in 
Assela hospital (80.7\%) (9), $95 \%$ confidence level and 0.05 margin of error, 10\% non-response rate. Calculated by the mentioned assumptions and the sample size were adjusted by correction formula due to the source population which was the total attend delivery services were one thousand one hundred ten (1110) in the study facility were less than ten thousand, so the final sample sizes were 217. The study participants were selected using a systematic sampling technique, in which the study participants were selected at every five intervals from all selected mothers. The data were collected by using two BSC midwifery and one MSc midwifery as supervisors for continuous follow up with structured interviewer questionnaire, which had sociodemographic characteristics, Obstetrics history, Health facility, and distance related respondent's satisfaction and service by health care provider related respondent satisfaction concerning questions. Data were collected using a structured interviewer-administered questionnaire after taking informed verbal consent from study participants.

\section{Data quality control}

The training was given for data collectors and supervisors for two days on the objective of the study and contents of the questionnaire. To ensure data quality, the instrument was pre-tested on $5 \%$ of the average of delivered mothers in Shenen Gibe Hospital, and based on the finding some modifications were made, data collectors were trained, day to day follow up and data was checked for completeness. The questionnaire was prepared in English, then translated to Afaan Oromo language to facilitate understanding and ensure consistency when administered to the respective respondents, then translated back again to the English language.

\section{Data processing and Analysis}

The collected data was cleaned, edited, coded, and entered into the computer for statistical analysis. The findings of the study were summarized and presented using tables and descriptive measures. Statistical inferences were made by using the chi-square test and the measure of association between dependent and independent variables.

\section{Ethical Consideration}

The study was approved by IRB committee of Jimma University, and permission was obtained from Jimma Medical Center. Informed verbal consent was obtained from each participant and confidentiality was kept by avoiding the patient identifier like name and patient medical record number from questionnaire.

\section{Results}

\section{Socio-demographic characteristics}

A total of 217 delivering mothers were included in the study with a response rate of $100 \%$. More than half (66.8) were within the age of 20-34 years and were married. One hundred thirty-eight respondents were 
belonging to the Oromo ethnic group which are (78.3\%). (Table 1)

Table 1: Socio demographic characteristics of delivered women in Jimma Medical Centeer, Jimma zone, Oromia regional state, south west Ethiopia, $2019(\mathrm{~N}=217)$. 


\begin{tabular}{|c|c|c|c|}
\hline Variables & Category & Frequency & Percentage \\
\hline \multirow[t]{3}{*}{ Age } & $<20$ & 36 & 16.6 \\
\hline & $20-34$ & 145 & 66.8 \\
\hline & $35-49$ & 36 & 16.6 \\
\hline \multirow[t]{4}{*}{ Marital status } & Single & 36 & 16.6 \\
\hline & Married & 145 & 66.8 \\
\hline & Divorced & 22 & 10.14 \\
\hline & Widowed & 14 & 6.5 \\
\hline \multirow[t]{5}{*}{ Ethnicity } & Oromo & 138 & 63.6 \\
\hline & Amhara & 28 & 13 \\
\hline & Dawro & 7 & 3.2 \\
\hline & Gurage & 36 & 16.6 \\
\hline & Others & 8 & 3.6 \\
\hline \multirow[t]{3}{*}{ Religion } & Muslim & 116 & 53.5 \\
\hline & Orthodox & 57 & 26.2 \\
\hline & Protestant & 44 & 20.2 \\
\hline \multirow[t]{4}{*}{ Educational status } & No formal education & 29 & 13.3 \\
\hline & Grade 1-8 & 36 & 16.7 \\
\hline & $9-12$ & 109 & 50.2 \\
\hline & $>12$ & 43 & 19.8 \\
\hline \multirow[t]{4}{*}{ Occupation } & Government employee & 36 & 16.7 \\
\hline & Merchant & 55 & 25.3 \\
\hline & Housewife & 102 & 47 \\
\hline & Others & 24 & 11 \\
\hline \multirow{3}{*}{$\begin{array}{l}\text { Economic } \\
\text { status (ETB/month) }\end{array}$} & $<500$ & 43 & 19.8 \\
\hline & $500-1000$ & 72 & 33.1 \\
\hline & $>1000$ & 102 & 47 \\
\hline \multirow[t]{2}{*}{ Residence } & Urban & 73 & 33.6 \\
\hline & Rural & 144 & 66.4 \\
\hline
\end{tabular}




\section{Obstetric characteristics of delivering mothers}

More than half 116(53.5\%) of women had 2-5 deliveries. One hundred thirty of delivering mothers referred for delivery service. $72.3 \%$ of delivering mothers have previous health facility delivery experience. More than three-fourth (83.4\%) of respondent had ANC visit. (Table 2)

Table 2: Obstetrics history of delivered mothers in Jimma Medical Center, Jimma zone, Oromia regional state, south west Ethiopia, $2019(\mathrm{~N}=217)$.

\begin{tabular}{|c|c|c|c|}
\hline Variables & Category & frequency & Percentage \\
\hline \multirow[t]{3}{*}{ Parity } & 1 & 87 & 40 \\
\hline & $2-5$ & 116 & 53.5 \\
\hline & $>5$ & 14 & 6.5 \\
\hline \multirow[t]{2}{*}{ Reason for visit } & Planned delivery & 87 & 40 \\
\hline & Referred delivery & 130 & 50.9 \\
\hline \multirow[t]{2}{*}{ Wanted status of pregnancy } & Wanted & 174 & 80.2 \\
\hline & Unwanted & 43 & 19.8 \\
\hline \multirow[t]{3}{*}{ Mode of delivery } & $S V D$ & 94 & 43.3 \\
\hline & cS & 80 & 36.9 \\
\hline & $A V D$ & 43 & 18.8 \\
\hline \multirow[t]{2}{*}{ Maternal outcome } & Normal & 181 & 83.4 \\
\hline & With complication & 36 & 16.6 \\
\hline \multirow[t]{5}{*}{ ANC follow up } & Yes & 181 & 83.4 \\
\hline & NO & 36 & 16.6 \\
\hline & 1 & 30 & 16.7 \\
\hline & $2-3$ & 70 & 38.7 \\
\hline & 4 or above & 81 & 44.6 \\
\hline \multirow[t]{2}{*}{ Previous health facility delivery } & Yes & 94 & 72.3 \\
\hline & No & 36 & 16.6 \\
\hline
\end{tabular}


Among delivering mothers $167(77 \%)$ of were satisfied with the facility distance. Seventy eight percent were satisfied with information of services. From the referred mothers $113(86.9 \%)$ were satisfied. Two hundred forty (98.6\%) of delivering mothers were satisfied with overall hospital compound. (Table 3)

Table 3: Distribution of variables related to respondent's satisfaction in Jimma Medical Center, Jimma, Ethiopia, 2019. 


\begin{tabular}{|c|c|c|c|}
\hline Variable & Category & Frequency & Percent \\
\hline \multirow[t]{2}{*}{ Satisfaction with facility distance } & Satisfied & 167 & 77 \\
\hline & Unsatisfied & 50 & 23 \\
\hline \multirow[t]{2}{*}{ Satisfaction with information service } & Satisfied & 141 & 77.9 \\
\hline & Unsatisfied & 40 & 22 \\
\hline \multirow[t]{2}{*}{ Satisfaction with referral link } & Satisfied & 113 & 86.9 \\
\hline & Unsatisfied & 17 & 13 \\
\hline \multirow[t]{2}{*}{ Satisfaction with toilet access } & Satisfied & 217 & 100 \\
\hline & Unsatisfied & 0 & 0 \\
\hline \multirow[t]{2}{*}{ Satisfaction with toilet cleanness } & Satisfied & 214 & 98.6 \\
\hline & Unsatisfied & 3 & 1.4 \\
\hline \multirow[t]{2}{*}{ Satisfaction with cleanness of delivering area } & Satisfied & 210 & 96.8 \\
\hline & Unsatisfied & 7 & 3.2 \\
\hline \multirow[t]{2}{*}{ Satisfaction with overall hospital compound } & Satisfied & 214 & 98.6 \\
\hline & Unsatisfied & 3 & 1.4 \\
\hline \multirow[t]{2}{*}{ Satisfaction with waiting time } & Satisfied & 205 & 94.5 \\
\hline & Unsatisfied & 12 & 5.5 \\
\hline \multirow[t]{2}{*}{ Satisfaction with respect } & Satisfied & 166 & 76.5 \\
\hline & Unsatisfied & 51 & 23.5 \\
\hline \multirow[t]{2}{*}{ Satisfaction with privacy } & Satisfied & 3 & 1.4 \\
\hline & Unsatisfied & 214 & 98.6 \\
\hline \multirow{2}{*}{$\begin{array}{l}\text { Satisfaction with the profession of delivery } \\
\text { attendant }\end{array}$} & Satisfied & 192 & 88.5 \\
\hline & Unsatisfied & 25 & 11.5 \\
\hline \multirow[t]{4}{*}{ Satisfaction with professional's sex } & $\begin{array}{l}\text { Satisfied with female } \\
\text { attendant }\end{array}$ & 43 & 59.7 \\
\hline & Unsatisfied & 29 & 40.3 \\
\hline & $\begin{array}{l}\text { Satisfied with male } \\
\text { attendant }\end{array}$ & 87 & 60 \\
\hline & Unsatisfied & 58 & 40 \\
\hline Satisfaction with overall delivery service & Satisfied & 145 & 66.8 \\
\hline
\end{tabular}




\section{Associated factors of maternal satisfaction among delivered mothers}

Variables which associated with satisfaction of delivery service were maternal educational status $\left(c^{2}=85.4, p<0.001\right)$, monthly income $\left(c^{2}=13.8, p<0.001\right.$ had association with maternal satisfaction (Table 4).

Table 4-Chi square analysis of factors associated with maternal satisfaction among delivering mothers in Jimma Medical Center, Jimma, Ethiopia, 2019.

\begin{tabular}{|c|c|c|c|c|c|c|}
\hline Variable & Category & Satisfied & Unsatisfied & $x^{2}$ & $D f$ & $\begin{array}{l}p- \\
\text { value }\end{array}$ \\
\hline \multirow[t]{4}{*}{ Educational status } & $\begin{array}{l}\text { No formal } \\
\text { education }\end{array}$ & 0 & 29 & \multirow[t]{4}{*}{85.4} & \multirow[t]{4}{*}{3} & \multirow[t]{4}{*}{$0.001^{*}$} \\
\hline & $1-8$ & 27 & 9 & & & \\
\hline & $9-12$ & 87 & 22 & & & \\
\hline & $>12$ & 31 & 28 & & & \\
\hline \multirow[t]{3}{*}{ Monthly income } & $<500$ & 22 & 21 & \multirow[t]{3}{*}{13.8} & \multirow[t]{3}{*}{2} & \multirow[t]{3}{*}{$0.001^{*}$} \\
\hline & $500-1000$ & 58 & 14 & & & \\
\hline & $>1000$ & 58 & 44 & & & \\
\hline \multirow[t]{3}{*}{ Parity } & 1 & 80 & 7 & \multirow[t]{3}{*}{19.4} & \multirow[t]{3}{*}{2} & \multirow[t]{3}{*}{$0.001^{*}$} \\
\hline & $2-5$ & 65 & 51 & & & \\
\hline & $>5$ & 0 & 14 & & & \\
\hline \multirow{3}{*}{$\begin{array}{l}\text { Distance from health } \\
\text { facility }\end{array}$} & $<50 \mathrm{~km}$ & 65 & 58 & \multirow[t]{3}{*}{13.5} & \multirow[t]{3}{*}{2} & \multirow[t]{3}{*}{$0.001^{*}$} \\
\hline & $50-100 \mathrm{~km}$ & 72 & 0 & & & \\
\hline & $>100 \mathrm{~km}$ & 6 & 16 & & & \\
\hline \multirow[t]{3}{*}{ Waiting time } & $<1$ hour & 168 & 44 & \multirow[t]{3}{*}{5.7} & \multirow[t]{3}{*}{2} & \multirow[t]{3}{*}{$0.05^{\star}$} \\
\hline & 1-2 hours & 2 & 3 & & & \\
\hline & $>2$ hours & 0 & 0 & & & \\
\hline \multirow[t]{2}{*}{ Cleanness of delivery area } & Clean & 144 & 65 & \multirow[t]{2}{*}{9.3} & \multirow[t]{2}{*}{1} & \multirow[t]{2}{*}{$0.001 *$} \\
\hline & Unclean & 0 & 8 & & & \\
\hline
\end{tabular}


Key: $*$ Variable statistically associated at P-value $\leq 0.05$

\section{Discussion}

This study showed that most of the patients interviewed were satisfied with the services they received at Jimma medical center. The magnitude of mothers who were satisfied with delivery care in this study was $66.8 \%$. This finding is almost comparable to that of Iran (61.2\%) (10), South Africa (64.57\%) (11), and the Amhara region (61.9\% (4). The percentage is high compared to other studies in developing countries India (42\%) (12), and Senegal (45.2\%) (13) But is low compared to New Zealand (90\%) (14). These variations maybe because of the difference in expectations of mothers in different societies or the type of health facilities. The finding is low compared to that of Debre Markos (81.7\%) (15), Arbaminch (90.2\%) (16), and Assela (80.7\%) (9). The difference might be due to the actual difference in socio-demographic characteristics of respondents, study time, study area, and study design.

In this study, all mothers were satisfied with access to the toilet. This is high compared to the study conducted in the Amhara region(4) where about two-third were satisfied, Debre Markos (about four-fifths were satisfied)(15) and also than that of Assela (only about half were satisfied) (9); this could be because of the relatively small area of the hospital compound where all facilities are found nearby, besides, the hospital has a separate latrine for delivering mothers so as their numbers are less concerning other hospitals, there will be no problem with accessibility.

Satisfaction with the cleanness of service given i.e. cleanness of the overall compound (98.6\%), cleanness of toilet (98.6\%), and delivering area (96.8\%) was also high compared to that of South Africa (72.1\%) (11); this may be due to the difference in expectation of the mothers. The result is comparable to some extent with that of the Amhara region (90\%) (4) but is high compared to the study in Assela (75\%) (9), this shows that the hospital has a clean environment.

Satisfaction with waiting time was $94.5 \%$, this is in line with that of Debre-Markos (95\%) (18) and is comparable to the Amhara region (90\%) (4) but is high compared to the Assela research (77\%) (8); the variation could be due to the relatively lower number of clients in the study hospital.

Health facility distance-related satisfaction was 77\% according to this study, this is higher than that of the Assela hospital which is 65\% (9); this could be due to the difference in accessibility and transportation, a distance of the health facilities from the center of their town also could be a reason.

Educational status was the other factor determining satisfaction; according to this study mothers who attain primary and secondary education were found to be more satisfied than higher education. This is a similar result with the study conducted in Arbaminch (16) in which mothers with lower education were more likely to be satisfied than the other. This may be because those with lower education can be satisfied with lower compromise than the others. 
Monthly income as a factor for satisfaction, mothers with higher income(> 1000) were more likely to be satisfied followed by those with middle income(500-1000ETB), the finding is different to that of the Assela(9) in which those with middle income were found to be satisfied but is in line with that of the Pakistan research; this could be because the higher-income ones compare the service with other private facilities in which they can get a better service and this may yield less satisfaction with the current one.

Parity was also associated with satisfaction, Primi Gravida mothers found to be more likely satisfied; the finding is similar to that of the Amhara and India $(4,12)$ region but was inconsistent with the study conducted in Assela (9) where the multi-Para were more likely to be satisfied. This could be because of the relatively high number of Primi in our study.

Distances from health facility as a factor, those who travel $50-100 \mathrm{~km}$ are more satisfied than those with $<50 \mathrm{~km}$, this is different from that of the Assela (9) and Amhara (4) culture, distribution of population and sample size of the study. Although unexpected it could be due to those population are likely to come from rural who may be satisfied with a less compromise than the urban one.

\section{Conclusion}

The magnitude of mothers satisfied with the delivery service was low compared to studies conducted in Ethiopia so far. Maternal educational status, parity, distance from the health facility, waiting time, and monthly income were associated with mothers' satisfaction with delivery service. Therefore, awareness creation should be given for the community for improving the quality of delivery service and mother's satisfaction as well as the further study should be done on the knowledge and skill of health care providers on delivery service.

\section{Abbreviations}

ANC: Antenatal Care; BSC:Bachelor of Science; EDHS.Ethiopia Demographic Health Survey; ETB:Ethiopia Birr, IRB: Institutional Review Board; JMC.Jimma Medical Center; KM:Kilo Meters; MSc:Master of Science

\section{Declarations}

\section{Data Availability}

The data used to maintenance the findings of this study are presented from the corresponding author upon request.

\section{Funding Statement}

The authors received no financial support for the research, authorship, and/or publication of this article.

\section{Conflicts of Interest}


The authors state that they conceive no conflicts of interest.

\section{Authors' Contributions}

GBB and MGN conducted the study and wrote the manuscript. LAW performed

statistical analysis, and critical revision of the manuscript. All authors read and approved the final manuscript.

\section{Authors details}

${ }^{1}$ School of Midwifery, Jimma University, P.O.Box 378, Jimma, Ethiopia.

${ }^{2}$ School of Nursing, Jimma University, P.O.Box 378, Jimma, Ethiopia.

${ }^{3}$ School of Midwifery, Jimma University, P.O.Box 378, Jimma, Ethiopia.

\section{Ethical approval and consent to participate}

The study protocol was reviewed and approved by the Jimma University Research Institutional Review Board (IRB). Informed consent was sought from the eligible Post-natal mothers before participation in the study. Participants were informed of the study objectives, that participation was voluntary, and their right to withdraw from the study at any time.

\section{Consent for publication}

Not applicable.

\section{Acknowledgments}

The authors are thankful to Jimma University, staff of Jimma Medical Center and the study participants.

\section{ORCID iD}

Lalisa Ayele: https://orcid.org/0000-0002-4368-0283

\section{References}

1. Federal Democratic Republic of Ethiopia Ministry of Health. Health Sector Development Program IV 2010/11 - 2014/15.

2. Opportunities for Africa's Newborns Practical data, policy and programmatic support for newborn care in Africa, 2014.

3. WHO: Trends in maternal mortality: 1990 to 2012, Geneva, Switzerland: WHO, UNICEF, UNFPA and The World Bank estimates? 
4. Tayelign A., Zegeye D. and Kebede Y., Mothers' satisfaction with referral hospital delivery service in Amhara region, Ethiopia: BMC pregnancy and child birth 2011,11:78

5. Ali M., Q. Mohammed and Seuc A., determinants of clients' satisfaction in obstetric care service in Pakistan,2014, 26(4).

6. Tefera, $T$. Ahmed, factors that determine health institutional delivery among pregnant women living in Agrafa town of Bale zone Oromia, south east Ethiopia. American journal of health research 2015 3(3) 130-134.

7. Ethiopian demographic Health Survey, 2016.

8. Assessment of causes of low skilled birth attendance coverage in selected woredas of Amhara, Oromia and SNNPR. World vision 2014.

9. Roza Amdemichael, Mesfin Tafa and Hailu Fekadu, Maternal Satisfaction with the Delivery Services in Assela Hospital, Arsi Zone, Oromia Region, 2014,4:12.

10. Taghavi s, et al; assessment of mother's satisfaction with the care of maternal care in specialized educational medical centers in obstetric and gynecologic diseases in north west Iran, JARCM 2015 $3(2): 77-86$

11. G lumadi and E Buch; patients'satisfaction with midwifery services at a regional hospital and its referring clinics in the Limpopo province of south Africa, journal of nursing and midwifery 2011 13(2) $: 14-20$

12. Ogala v. et al.; women level of satisfaction with maternal health service in Jharkhand, USAID/INDIA 2012

13. Oliwaka M., et al, assessment of maternal satisfaction with facility based child birth care in the rural region of Tombacouda, Senegal, Africa journal of reproductive health, 2014 18(4)

14. Kahneman p.et al.; Nagoya j medical science 2015(77): 69-79

15. Kurabachew Bitew, Mekonnen Ayichiluhm, and Kedir Yimam, Maternal Satisfaction on Delivery Service and Its Associated Factors among Mothers Who Gave Birth in Public Health Facilities of Debre Markos Town, Northwest Ethiopia, 2015.

16. Dewana z. et al., client perspective assessment of women satisfaction towards labor and delivery care service in public health facilities in Arba Minch town and the surrounding district, Gamo Gofa zone south Ethiopia, journal of reproductive health ,2014. 